\title{
A Current Control Scheme of a Grid-connected Inverter to Enhance Power Quality in Distributed Generation
}

\author{
Kyeong-Hwa Kim \\ Department of Electrical and Information Engineering \\ Seoul National University of Science and Technology \\ 232 Gongneung-ro, Nowon-gu, Seoul, 139-743, Korea \\ e-mail:k2h1@seoultech.ac.kr
}

\begin{abstract}
To enhance the power quality in distributed generation (DG) systems even under distorted grid, a high performance current control scheme of a grid-connected inverter is presented. The proposed scheme is achieved through the model decomposition of inverter voltage equations into the fundamental and harmonic components. Based on the derived models, the harmonic components are regulated by the predictive control approach to suppress undesired harmonic components quickly. To design the harmonic current controller separately, the harmonic components are extracted through the fourth order band pass filter (BPF). To demonstrate the validity of the proposed current control scheme, a laboratory prototype grid-connected inverter has been constructed using digital signal processor (DSP) TMS320F28335 based controller. The effectiveness of the proposed scheme is proved through comparative simulation and experimental results.
\end{abstract}

Keywords-component; current control; digital signal processor; distributed generation; grid-connected inverter; power quality.

\section{INTRODUCTION}

Over the last ten years, there has been an increasing interest in the renewable energy sources because of the worldwide energy crisis created by the depletion of fossil energy and the greenhouse gas emission limit. Among various renewable energy resources connected to the electrical grid, wind power generation is recognized as the most competitive and economic one, which leads to a rapid growth in the global wind power generation capacity [1], [2].

In a variable-speed permanent magnet synchronous generator (PMSG) based wind power system, a back-to-back converter is generally located between the generator and grid to convert the generator output power in variable voltage and frequency to the fixed voltage and frequency of grid.

The back-to-back converter consists of two power electronics converters. One is the three-phase converter to convert the generated AC power into DC power and the other is the grid connected inverter to convert the DC power into $\mathrm{AC}$ power in grid frequency. Whereas the three-phase converter controls the generator speed to draw the maximum output power from wind turbine, the grid connected inverter controls the frequency and active/reactive powers for grid connection.

As the level of wind energy penetration in the electrical power system is increased, the improvement of power quality has become a very important issue in distributed generation (DG) systems. The harmonic pollution caused by nonlinear loads in electrical networks brings about distorted grid voltage, power losses and heating in the electrical equipment [3]. To limit the amount of harmonic current injected into utility grid to be below the specified values, the harmonic restriction standards such as IEEE-519 or IEC 61000-3-2 have been published [4].

When the generated electrical energy from renewable energy resources is delivered to grid through the gridconnected inverter, the inverter should provide fast response, zero steady-state error, and robustness to disturbance. In addition, the grid-connected inverter should effectively compensate the harmonic, imbalance, and reactive power. Traditionally, the simple PI control is employed to control the grid-connected inverter. Using the PI controller, however, the disturbance due to the harmonics under the distorted grid cannot be effectively compensated.

There have been various research works on the power quality improvement of DG systems such as harmonic compensation or elimination strategies. The harmonic compensation scheme using the PI control in the rotating reference frame of each harmonic frequency has been proposed [3]-[5]. These harmonic controllers are designed to compensate each harmonic term selectively. Another schemes use the repetitive control [6] or sliding mode control [7] to suppress undesired harmonic components. The sliding mode control scheme has good disturbance rejection and robustness even under the distorted grid condition. However, this scheme inherently shows the undesired chattering problems, making the DG system have low power quality. The repetitive control scheme often gives slow response and performance degradation in disturbance rejection under nonperiodic harmonics because of the delay requirement.

To enhance the power quality of DG system such as wind power, a current control scheme of a grid-connected inverter is presented in this paper. The proposed scheme is achieved through the model decomposition of inverter voltage equations into the fundamental and harmonic components. 
Based on the derived models, the harmonic components are regulated by the predictive control approach to suppress undesired harmonic components quickly. Thus, a current control performance can be significantly improved even in the presence of distorted grid condition. To verify the effectiveness of the proposed harmonic suppression scheme, a laboratory prototype grid-connected inverter has been constructed using digital signal processor (DSP) TMS320F28335 [8]. The current control performance of the proposed scheme has been proven through comparative simulations and experimental results.

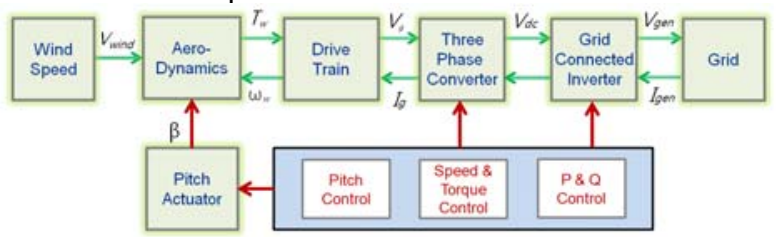

Figure 1. Configuration of a grid-connected wind power system.

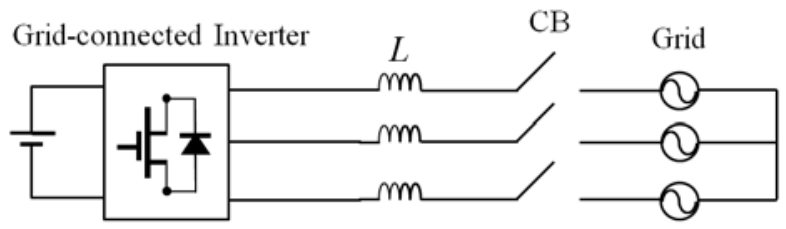

Figure 2. Grid-connected inverter in DG system.

\section{INVERTER MODEL}

Fig. 1 shows the configuration of a grid-connected inverter in DG systems such as a wind power system [9]. The grid-connected inverter is generally located between the generator and grid to convert the generator output power in variable voltage and frequency to the fixed voltage and frequency of grid.

Fig. 2 shows a grid-connected inverter in DG system. Considering the utility grid and the output of a three-phase voltage source inverter as ideal voltage sources, the voltage equations of a grid-connected inverter in the synchronously rotating reference frame can be expressed as follows:

$$
\begin{gathered}
u_{q s}=R i_{q s}+L p i_{q s}+\omega L i_{d s}+e_{q s} \\
u_{d s}=R i_{d s}+L p i_{d s}-\omega L i_{q s}+e_{d s} .
\end{gathered}
$$

where $u_{q s}$ and $u_{d s}$ are the $q$-axis and $d$-axis inverter output voltages, respectively, $e_{q s}$ and $e_{d s}$ are the $q$-axis and $d$-axis grid voltages, respectively, $i_{q s}$ and $i_{d s}$ are the $q$-axis and $d$ axis inverter currents, respectively, $L$ is the filter inductance, $R$ is the filter resistance, $\omega$ is the grid angular frequency, and $p$ is the differential operator.

\section{PROPOSED HARMONIC COMPENSATION}

To improve the power quality of a DG system even under distorted voltage condition, the harmonic current components should be compensated in the output of a gridconnected inverter. Generally, the harmonic components in
DG system are not significant as compared with the fundamental component. However, using the conventional PI current controller, the current regulation as well as the suppression of undesired harmonic components cannot be achieved at the same time. To overcome this limitation in this paper, the voltage equations of a grid-connected inverter are divided into the fundamental and harmonic models through model decomposition. For this purpose, the grid voltages, inverter currents, and inverter output voltages are defined as follows:

$$
\begin{aligned}
& e_{q s}=E_{q s}+e_{q s h} \\
& e_{d s}=E_{d s}+e_{d s h} \\
& i_{q s}=I_{q s}+i_{q s h} \\
& i_{d s}=I_{d s}+i_{d s h} \\
& u_{q s}=U_{q s}+u_{q s h} \\
& u_{d s}=U_{d s}+u_{d s h}
\end{aligned}
$$

where the subscript " $h$ " denotes the variables in harmonic components, and $E, I$, and $U$ represent DC quantities, respectively. By substituting (3)-(8) into (1) and (2), the voltage equations of a grid-connected inverter can be decomposed in the fundamental and harmonic components as follows:

$$
\begin{aligned}
& U_{q s}=R I_{q s}+L p I_{q s}+\omega L I_{d s}+E_{q s} \\
& U_{d s}=R I_{d s}+L p I_{d s}-\omega L I_{q s}+E_{d s} \\
& u_{q s h}=R i_{q s h}+L p i_{q s h}+\omega L i_{d s h}+e_{q s h} \\
& u_{d s h}=R i_{d s h}+L p i_{d s h}-\omega L i_{q s h}+e_{d s h} .
\end{aligned}
$$

While (9) and (10) represent the fundamental model of the inverter voltage equations, (11) and (12) represent the harmonic model. To control the main power flow in the fundamental component, the PI decoupling current controller is employed using (9) and (10) as follows:

$$
\begin{gathered}
U_{q s}^{*}=\left(K_{P}+K_{I} / s\right)\left(I_{q s}^{*}-I_{q s}\right)+\omega L I_{d s}+E_{q s} \\
U_{d s}^{*}=\left(K_{P}+K_{I} / s\right)\left(I_{d s}^{*}-I_{d s}\right)-\omega L I_{q s}+E_{d s}
\end{gathered}
$$

where the symbol “*” denotes the reference quantities, and $K_{P}$ and $K_{I}$ are the PI controller gains, respectively. To eliminate undesired harmonic current components effectively, the predictive control approach is employed based on the harmonic models in (11) and (12) as follows:

$$
\begin{aligned}
& u_{q s h}^{*}=R i_{q s h}+\frac{L}{T}\left[i_{q s h}^{*}-i_{q s h}\right]+\omega L i_{d s h}+e_{q s h} \\
& u_{d s h}^{*}=R i_{d s h}+\frac{L}{T}\left[i_{d s h}^{*}-i_{d s h}\right]-\omega L i_{q s h}+e_{d s h}
\end{aligned}
$$

where $T$ is the sampling period. Using (13) through (16), the inverter reference voltages of the proposed control scheme are computed as follows:

$$
\begin{aligned}
& u_{q s}^{*}=U_{q s}^{*}+u_{q s h}^{*} \\
& u_{d s}^{*}=U_{d s}^{*}+u_{d s h}^{*} .
\end{aligned}
$$




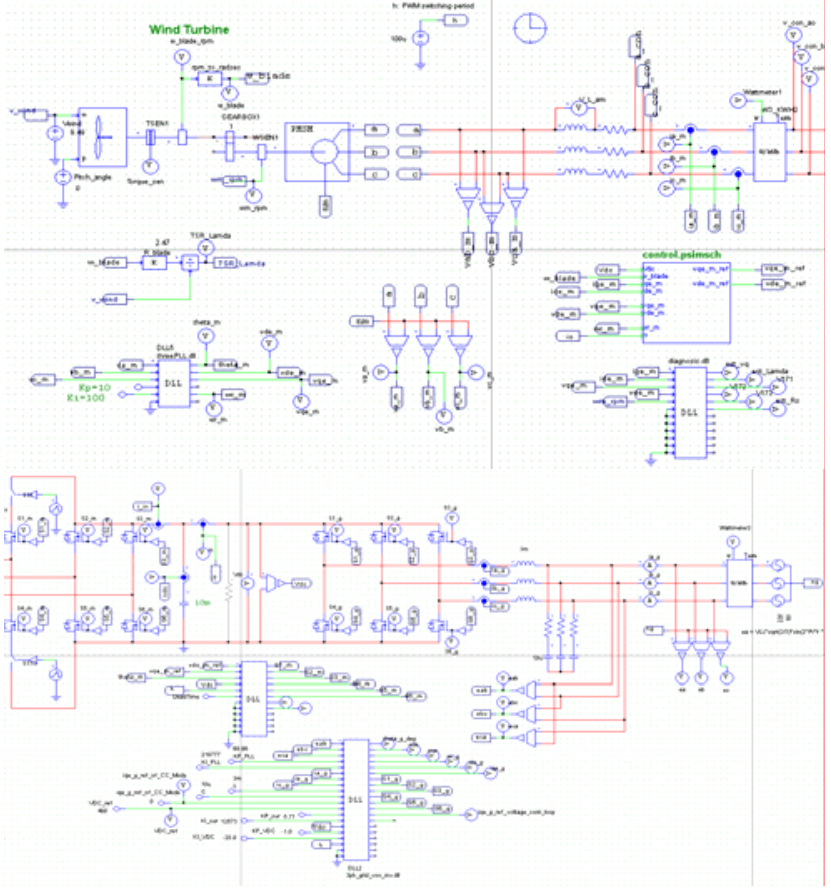

Figure 3. Simulation configuration for the grid-connected inverter.

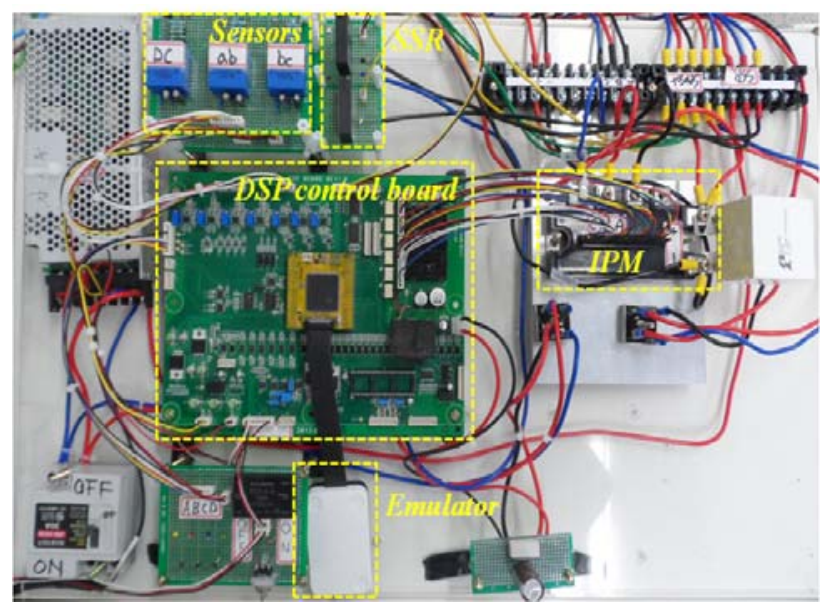

Figure 4. DSP-based controller.

\section{SYSTEM CONFIGURATION}

The entire simulation is done by using the PSIM software and the main controller is implemented with the PSIM DLL block. Fig. 3 shows the simulation structure for the gridconnected inverter. The sampling period is set to $100 \mu \mathrm{sec}$ both in the simulations and experiments. To apply the computed reference voltages to a grid-connected inverter, the symmetrical space vector PWM technique is employed.

Fig. 4 shows DSP-based controller for a grid-connected inverter. The whole control algorithms are implemented using 32-bit floating-point DSP TMS320F28335 with 150 $\mathrm{MHz}$ clock frequency [8]. DSP TMS320F28335 has 256K word of on-chip flash memory and some peripherals such as an internal 12-bit AD converter and 16-bit PWM port. The intelligent power module (IPM) is employed for three-phase grid-connected inverter. The inverter phase currents are detected by the Hall-effect devices and are converted through internal 12-bit $\mathrm{A} / \mathrm{D}$ converters, where the resolution of current is $18 / 2^{11}$ [A]. To isolate between the grid-connected inverter and grid, three-phase wye-delta double winding transformer is employed.

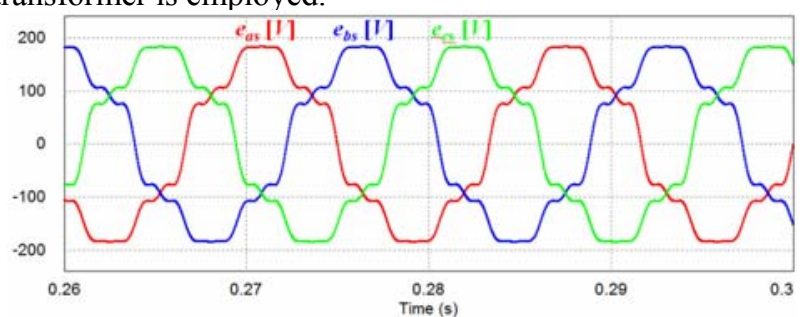

Figure 5. Three-phase distorted grid voltages used in simulations.

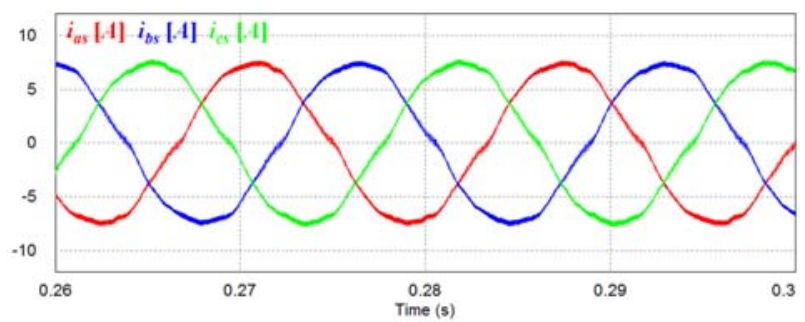

(a)

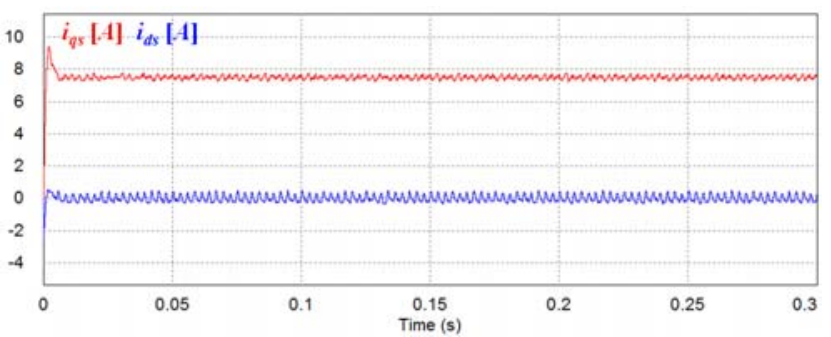

(b)

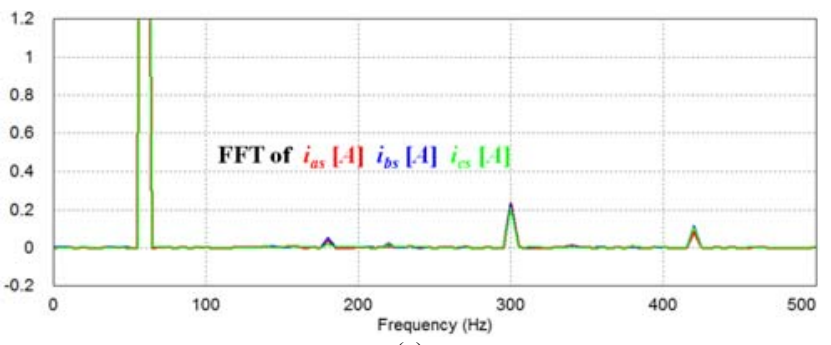

(c)

Figure 6. Simulation results under distorted grid voltages with the PI current control: (a) three-phase currents, (b) $q$ - and $d$-axis inverter currents, (c) FFT results of phase currents.

\section{SimUlation AND EXPERIMENTAL RESUltS}

Fig. 5 shows three-phase distorted grid voltages used in the simulation study. For distorted grid voltages, the harmonic voltages are considered as follows: $10 \%$ of the 
fifth-order, $7.1 \%$ of the seventh-order, $4.5 \%$ of the eleventhorder, and $3.8 \%$ of the thirteenth-order harmonics, respectively. These harmonic components are injected into the ideal grid voltage.

Fig. 6 shows the simulation results under distorted grid voltages only with the PI current control scheme. It is observed in these figures that the harmonic components are not suppressed well. Three-phase currents are severely distorted and large harmonic components exist in the fifth and seventh order due to the distorted grid voltage.

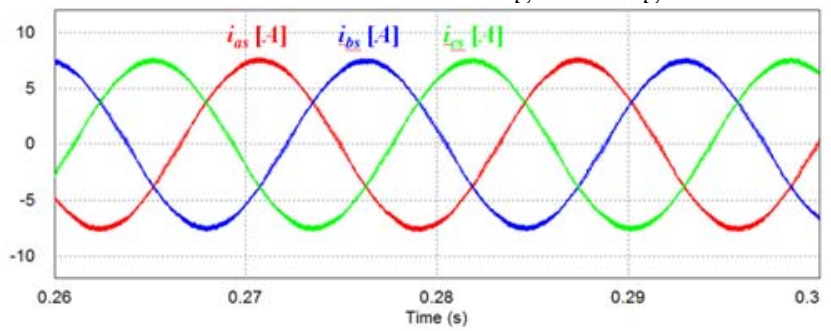

(a)

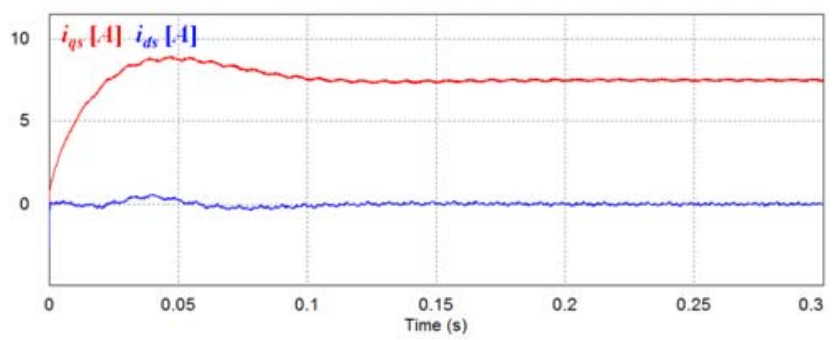

(b)

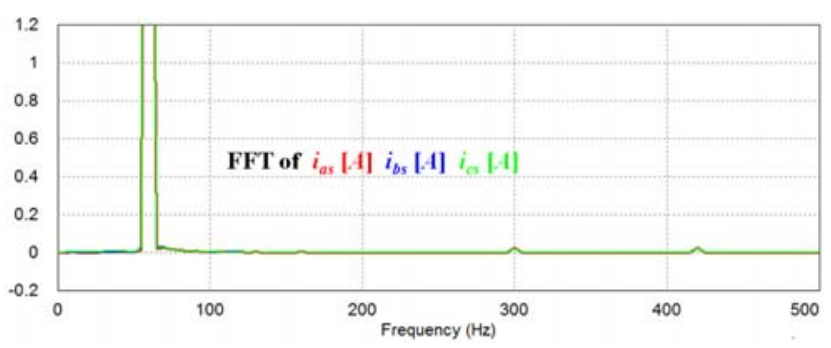

(c)

Figure 7. Simulation results under distorted grid voltages with the proposed scheme: (a) three-phase currents, (b) $q$ - and $d$-axis inverter currents, (c) FFT results of phase currents.

Fig. 7 shows the simulation results under distorted grid voltages with the proposed scheme where the predictive control approach is employed using the derived harmonic model to compensate undesired harmonics. The operating conditions are the same with Fig. 6 . It is clearly seen that the current waveforms are much more sinusoidal as compared with Fig. 6 and the fifth and the seventh harmonic components are considerably reduced.

Fig. 8 shows the measured actual three-phase grid voltages in the laboratory. The actual grid voltages are highly distorted with major harmful low order harmonic components. In the experiments, these distorted grid voltages are used for grid connection of inverter.

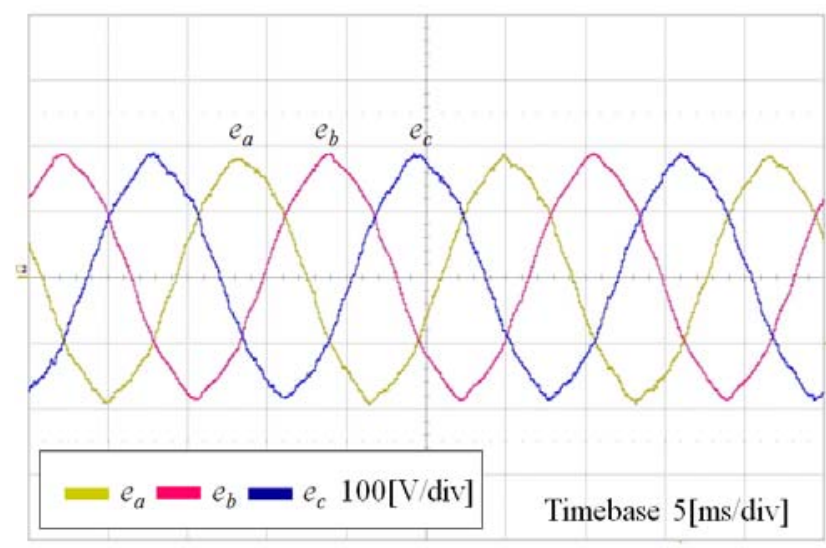

Figure 8. Three-phase distorted grid voltages used in experiments.

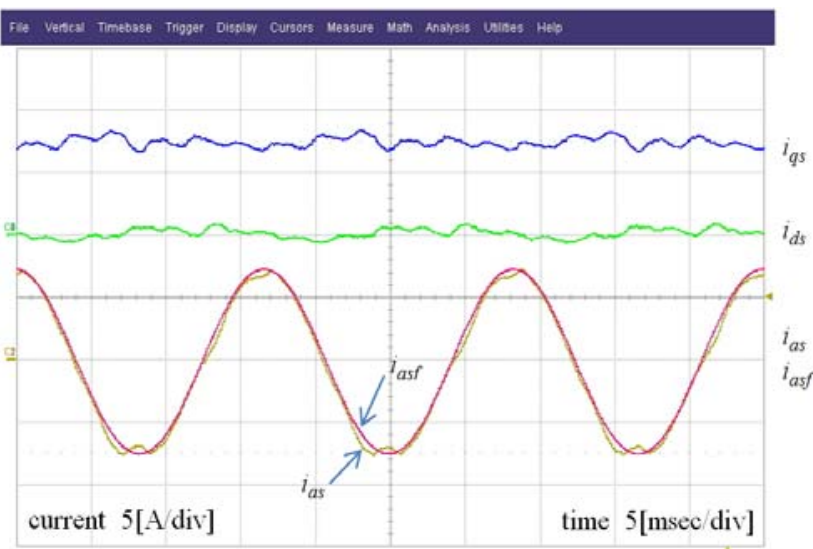

Figure 9. Experimental results under distorted grid voltages with the PI current control.

Fig. 9 shows the experimental results under distorted grid voltages only with the PI current control. From the top, Fig. 9 shows the $q$-axis current, $d$-axis current, $a$-phase current, and the fundamental current component $i_{a s f}$ extracted from $a$ phase current by the band pass filter, which indicates how much the phase current deviates from the pure sinusoid. As a result of poor harmonic rejection capability by the PI controller, the harmonic currents are significantly large and the $q$-axis and $d$-axis currents have quite fluctuating waveforms. Also, these waveforms clearly show the actual $a$-phase current is quite non-sinusoidal and distorted.

On the other hand, Fig. 10 shows the experimental results of the proposed control scheme under the same distorted grid voltages. As a result of an effective suppression of the harmonic components by the proposed scheme, the harmonic currents are significantly decreased, and the $q$-axis and $d$ axis currents can be regulated to the reference better with a small tracking error. 


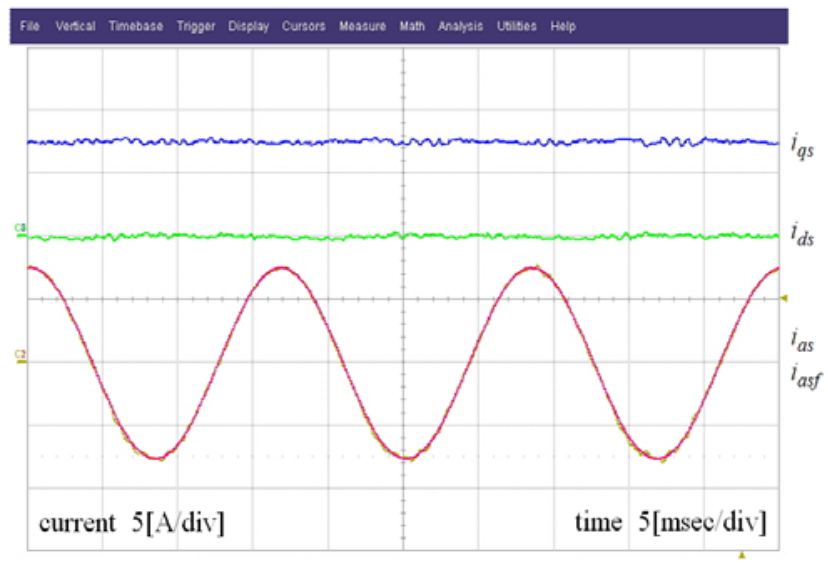

Figure 10. Experimental results under distorted grid voltages with the proposed scheme.

\section{CONCLUSION}

To enhance the power quality in DG systems even under distorted grid condition, a high performance current control scheme of a grid-connected inverter has been presented. The proposed scheme is achieved through the model decomposition of inverter voltage equations into the fundamental and harmonic components. Based on the derived models, the harmonic components are regulated by the predictive control approach to suppress undesired harmonic components effectively. To demonstrate the validity of the proposed current control scheme, a laboratory prototype grid-connected inverter has been constructed using DSP TMS320F28335 based controller. Through the integrated simulation studies and comparative experiments, the validity of the proposed current control scheme has been proved. As a result, the proposed control scheme can be usefully utilized in a grid-connected inverter for DG systems in the presence of distorted grid condition.

\section{ACKNOWLEDGMENT}

This research was supported by Basic Science Research Program through the National Research Foundation of Korea (NRF) funded by the Ministry of Education (NRF2014R1A1A2056436).

\section{REFERENCES}

[1] Z. Chen, J. M. Guerrero, and F. Blaabjerg, "A review of the state of the art of power electronics for wind turbines," IEEE Trans. on Power Electronics, vol. 24, no. 8, pp. 1859-1875, 2009

[2] I. Munteanu, S. Bacha, A. Bratcu, J. Guiraud, and D. Roye, "Energy-reliability optimization of wind energy conversion systems by sliding mode control," IEEE Trans. on Energy Conversion, vol. 23, no. 3, pp. 975-985, 2008.

[3] C. Lascu, L. Asiminoaei, I. Boldea, and F. Blaabjerg, "High performance current controller for selective harmonic compensation in active power filters," IEEE Trans. Power Electronics, vol. 22, no. 5, pp. 1826-1835, 2007.

[4] Q. N. Trinh, and H. H. Lee, "An advanced current control strategy for three-phase shunt active power filters," IEEE Trans. Industrial Electronics, vol. 60, no. 12, pp. 5400-5410, 2013.

[5] C. Lascu, L. Asiminoaei, I. Boldea, and F. Blaabjerg, "Frequency response analysis of current controllers for selective harmonic compensation in active power filters," IEEE Trans. Industrial Electronics, vol. 56, no. 2, pp. 337-347, 2009.

[6] G. Escobar, P. G. Hernandez-Briones, P. R. Martinez, M. Hernandez-Gomez, and R. E. Torres-Olguin, "A repetitivebased controller for the compensation of harmonic components," IEEE Trans. Industrial Electronics, vol. 55, no. 8, pp. 3015-3158, 2008.

[7] A. Karaarslan, and I. Iskender, "Average sliding control method applied on power factor correction converter for decreasing input current total harmonic distortion using digital signal processor," IET Power Electronics, vol. 5, no. 5, pp. 617-626, 2012.

[8] TMS320F28335 Digital Signal Controller (DSC) - Data Manual. Texas Instrument, 2008

[9] K. H. Kim, "Performance investigation and observer-based condition monitoring scheme for a PMSG-based gridconnected wind power system under switch open fault," SERSC Int. Journal of Control and Automation, vol. 6, no. 4, pp. 483-498, 2013. 